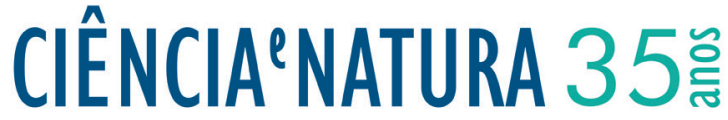

\section{Na busca da Interdisciplinaridade: Percepções sobre a formação inicial de professores de Ciências da Natureza}

\author{
In search of Interdisciplinarity: Perceptions of initial teachers formation in Nature's \\ Sciences
}

\author{
Rafaele Rodrigues de Araújoํㅜ, Cristiane da Cunha Alves² \\ ${ }^{1}$ Mestre , Universidade Federal do Rio Grande,Porto Alegre, Brasil \\ ${ }^{2}$ Acadêmica em Ciências da Natureza, Universidade Federal do Pampa, Dom Pedrito, Brasil
}

\begin{abstract}
Resumo
O presente trabalho objetiva trazer discussões sobre a interdisciplinaridade em um curso de formação de professores em Ciências da Natureza da Universidade Federal do Pampa - Campus Dom Pedrito, a qual iniciou seu funcionamento no ano de 2012. A partir do Projeto de Pesquisa "Ensino de Ciências da Natureza: Diálogos Interdisciplinares em rodas de formação", cuja finalidade é estudar e discutir a interdisciplinaridade dentro do curso de formação, realizou-se uma pesquisa a fim de entender a percepção dos docentes e discentes do curso sobre a prática interdisciplinar. O estudo utilizou como método de trabalho a Análise Textual Discursiva, de Moraes $\mathcal{E}$ Galiazzi (2007), podendo-se detectar que, tanto para professores quanto para alunos, a interdisciplinaridade é vista como uma integração de áreas, em que o diálogo entre elas é parte essencial para a prática, melhorando, assim, o ensino e aprendizagem. No entanto, um questionamento permanece: como fazer com que o discurso e a prática se tornem pontos convergentes?
\end{abstract}

Palavras-chave: Interdisciplinaridade; Ciências da Natureza; Formação de professores.

\begin{abstract}
This paper aims to bring discussions about interdisciplinarity in a training course for teachers in the Nature's Sciences of the Federal University of Pampa - Campus Dom Pedrito, which started its operation in year of 2012. From the Project of Research "Education in Nature's Sciences: Interdisciplinary Dialogues in wheels of formation", whose purpose is to study and discuss interdisciplinarity within the training course, we carried out a survey to understand the perception of teachers and students of the course on interdisciplinary practice. The study used as a working method the Discourse Textual Analysis, of Moraes \& Galiazzi (2007), and we can detect that both teachers and students the education is seen as an integration of areas in which the dialogue between them is essential for the practical, thus improving the teaching and learning. However, one question remains: How to make the discourse and practice become convergent points?
\end{abstract}

Keywords: Interdisciplinarity; Nature's Sciences; Teacher of formation. 


\section{Introdução}

A temática "interdisciplinaridade" tem ocasionado, há um longo tempo, diversas discussões, inseridas em qualquer contexto em que envolva a produção de conhecimento por várias áreas. Ultimamente, essa problematização se tornou mais expressiva na área da educação, com o retorno e surgimento dos cursos de formação de professores interdisciplinares. A formação de docentes com esse perfil, que permite a atuação em uma área ampla do conhecimento, faz com que vários pontos sejam repensados dentro do tema interdisciplinaridade, desde a teoria até a prática.

Os documentos oficiais, resoluções e diretrizes, permitem perceber como ocorre, na teoria, a mudança, assim como o movimento histórico da inserção da interdisciplinaridade na educação, que vem marcando e sinalizando para o enfoque da prática interdisciplinar dentro dos meios de ensino, sejam eles Educação Básica ou Ensino Superior.

As diretrizes curriculares são documentos que se constituem de normas obrigatórias para a Educação Básica e orientam o planejamento curricular das escolas e dos sistemas de ensino. A Resolução $\mathrm{n}^{\mathrm{o}} 2$ de 30 de janeiro de 2012, do Conselho Nacional da Educação (CNE), traz uma nova organização curricular para o Ensino Médio, expondo que o ensino parte de uma base comum nacional e uma diversificada que não pode constituir blocos que não se interliguem, mas deve ser um todo integrado. Dessa forma, o ensino recebido no Ensino Médio deve garantir tanto conhecimentos e saberes comuns necessários a todos os estudantes quanto uma formação que considere a diversidade, as características locais e especificidades regionais.

A finalidade desta nova resolução é de modificar o Ensino Médio atual, a fim de contribuir para a qualificação da formação dos estudantes, a partir de uma metodologia que proporcione uma formação mais ampla, organizando o currículo em áreas do conhecimento: Linguagens; Matemática; Ciências da Natureza e Ciências Humanas. Sendo assim, a proposta de trabalho, dentro das novas diretrizes, é que as áreas utilizem a contextualização e a interdisciplinaridade, garantindo, assim, o diálogo entre os componentes curriculares.

A contextualização, de acordo com os documentos oficiais, seria um recurso didático para problematizar a realidade vivida pelo estudante, extraí-la do seu contexto e projetá-la para a análise, ou seja, consiste em elaborar uma representação do mundo para melhor compreendê-lo (BRASIL, 2000). A articulação interdisciplinar, promovida por um aprendizado contextualizado, de acordo com Brasil (2002), não deve ser vista como um produto adicional a ser oferecido eventualmente, pois sem ela o conhecimento desenvolvido pelo estudante estará fragmentado e será ineficaz, isso porque será nesse contexto que ocorrerá efetiva união entre linguagens e conceitos comuns às várias disciplinas, através da interdisciplinaridade.

A reformulação curricular no Ensino Médio apresenta a contextualização ao lado da interdisciplinaridade como alternativas às práticas escolares tradicionais que são puramente fragmentadas e desprovidas de significação, baseadas em um currículo que prega, na maior parte das vezes, uma dicotomia histórica entre teoria e prática ou entre o ensino propedêutico e o ensino profissionalizante (MIRANDA et al., 2010).

A partir do exposto, percebe-se na proposta a busca do ensino desfragmentado, em que as áreas do conhecimento se reorganizam em unidades maiores, visando uma abordagem interdisciplinar. Assim, emergem novas concepções sobre a interdisciplinaridade, discutidas na esfera acadêmica e na esfera escolar mais abrangente, onde as inter-relações entre as áreas são fomentadas, na busca de um eixo central de estudo.

Dessa maneira, a partir dessas mudanças nas avaliações e no sistema de ensino, surge um novo olhar nos cursos de graduação em Licenciatura no Ensino Superior, fazendo com que cursos de Licenciaturas Interdisciplinares sejam criados, com foco nas áreas de conhecimento e não mais na formação disciplinar fragmentada tradicional.

Devido a não se ter, no momento, legislações e normativas que sirvam de base para estruturar e dar referências às licenciaturas interdisciplinares, ocorrem inúmeras dúvidas, pois essa nova formação é algo recente e, em muitos casos, desconhecida, necessitando de novas discussões e concepções. Essas dúvidas se tornam cada vez mais constantes, seja para os docentes formadores, seja para os graduandos, já que estes se inserem em um curso sem saber realmente seu futuro dentro da escola e da sociedade, uma vez que as diretrizes estão sendo estudadas, discutidas e problematizadas.

Diante da falta de embasamento teórico e metodológico sobre o ensino interdisciplinar, alguns questionamentos aparecem: como será a atuação dessa nova geração de professores que está sendo formada na perspectiva do trabalho interdisciplinar? Como os professores formadores devem atuar em um curso interdisciplinar, uma vez que suas formações foram em áreas específicas?

Nesse sentido, alguns pontos devem ser levados em consideração, já que a literatura entende, de forma geral, que a interdisciplinaridade depende do diálogo entre as áreas do conhecimento. O diálogo se faz necessário, pois, como explicita Fazenda (2003, p. 38-39): "se a palavra tem sentido, se falar é falar a alguém, é comunicar, se a palavra que não tem sentido se esvazia, um programa de ensino linear que configure disciplinas isoladas, incomunicáveis, não tem sentido, é vazio". Ao contrário de outras perspectivas, como Jantsch e Bianchetti (2011, p. 25), que expõem que "um grupo pode ser mais homogêneo e superficial que o indivíduo que busca recursos de várias ciências para explicar determinado processo". Podemos perceber que, até mesmo dentro dos estudos teóricos encontrados, temos uma contra- 
dição na concepção e prática interdisciplinar, pois, sob determinados pontos de vista, a interdisciplinaridade não depende somente do diálogo, mas também da busca de entendimento em várias ciências, assim o diálogo seria algo intrínseco à ela.

Quando fala-se de diálogo, surge um ponto que pode ser discutido dentro desse contexto, a solidão interdisciplinar ${ }^{1}$, uma vez que a formação é por áreas do conhecimento, não necessitando, neste caso, de uma conversa com docentes das outras áreas que compõem as Ciências da Natureza. Essa solidão é algo que, a partir dessa análise, poderá emergir nos futuros acadêmicos formados nesses cursos, visto que serão professores com formação interdisciplinar, mas que não precisarão de seus pares para fazer uma prática interdisciplinar. De acordo com Luck (2001), a interdisciplinaridade é o processo de integração e engajamento de educadores, num trabalho conjunto, de interação das disciplinas do currículo escolar entre si e com a realidade, de modo a superar a fragmentação do ensino e do conhecimento, e que tem por finalidade a formação integral dos alunos.

Além disso, outras indagações são feitas, pois como podemos saber se, a partir de um curso denominado interdisciplinar, a formação do egresso se constitui interdisciplinarmente? Se considerarmos Ferreira (1999), que explicita a interdisciplinaridade como uma atitude, ou seja, uma externalização de uma visão de mundo que, no caso, é holística, quem garante que o acadêmico formado irá, em sua prática de sala de aula, ter atitudes e posicionamentos interdisciplinares? Dessa forma, essas questões sobre a formação inicial de professores interdisciplinares em uma área do conhecimento são o que necessitam ser investigadas dentro dos cursos de licenciaturas interdisciplinares.

$\mathrm{Na}$ busca de esclarecer e perceber os desafios que aparecem ao formar profissionais que serão interdisciplinares, esse trabalho pretende discutir e problematizar esse tema, tendo como questão norteadora: Como ocorre a constituição inicial do conceito de interdisciplinaridade, no ponto de vista de formadores e licenciandos que se encontram inseridos em um curso de formação de professores interdisciplinares, e como os mesmos percebem a interdisciplinaridade dentro desse curso?

Para isso, a pesquisa analisou as falas dos sujeitos envolvidos no curso de Licenciatura em Ciências da Natureza da Universidade Federal do Pampa (UNIPAMPA) do Campus Dom Pedrito. As mesmas foram coletadas através das ações realizadas no Projeto de Pesquisa "Ensino de Ciências da Natureza: Diálogos interdisciplinares em rodas de formação", cujo objetivo é investigar quais as concepções sobre a formação inicial de professores de ciências e como essas se constroem através das ações do ensino interdisciplinar e contex1 A "solidão interdisciplinar" é uma expressão utilizada nesse texto para explicar a sentimento do licenciado formado nesses cursos interdisciplinares, visto que será alguém formado interdisciplinarmente que não necessitará, obrigatoriamente, de seus pares para fazer suas práticas. tualizado no ensino de Ciências.

\subsection{Interdisciplinaridade: O quê e como?}

Para ocorrer a problematização de como poderá ser desenvolvida a interdisciplinaridade, nas práticas, dentro dos cursos de Licenciaturas Interdisciplinares, inicialmente é necessário explorar a conceituação de interdisciplinaridade. Segundo Yared (2008 apud SUERO, 1986, p. 18), a interdisciplinaridade retoma a palavra disciplina:

[...] a interdisciplinaridade sugere um conjunto de relações entre disciplinas abertas sempre a novas relações que se vai descobrindo. Interdisciplinar é toda interação existente dentre duas ou mais disciplinas no âmbito do conhecimento, dos métodos e da aprendizagem das mesmas. Interdisciplinaridade é o conjunto das interações existentes e possíveis entre as disciplinas nos âmbitos indicados.

No Brasil, a interdisciplinaridade começa a ser discutida por volta do final da década de 60, com sérias distorções, na verdade como um modismo, pois ela vinha sendo problematizada em outros países. Hilton Japiassú, primeiro brasileiro com produção significativa na área, caracterizava interdisciplinaridade como a intensidade da troca entre os especialistas e pelo grau de interação das disciplinas em um projeto de pesquisa. No entanto, esse autor percebia a falta da interdisciplinaridade, isto é, o ensino por disciplinas, como uma doença no saber.

Outra pesquisadora que se destaca pelos escritos sobre a temática é Ivani Fazenda, trazendo como um conceito de interdisciplinaridade uma junção de disciplinas, mas enfatiza que para colocá-la em prática se necessita de ousadia e de busca em frente ao conhecimento.

Ari Paulo Jantsch \& Lucídio Bianchetti (2011), atualmente, abordam a interdisciplinaridade como algo além da filosofia do sujeito, levando em consideração uma concepção a-histórica, ou seja, a interdisciplinaridade deve ser vista como um tema que transcende a ação do sujeito sobre o objeto, de modo a tornar o sujeito absoluto na construção do conhecimento e do pensamento. Como explicitam os autores:

Não negamos as possíveis contribuições à filosofia do sujeito na produção historicamente acumulada do conhecimento. Contudo, seja na circunscrição idealista (...) ou em outra qualquer que incorra em a-historicidade, não vemos substrato suficiente para configurar a construção histórica do objeto "interdisciplinaridade". (JANTSCH \& BIANCHETTI, 2011, p. 20)

A interdisciplinaridade, nesse caso, é vista sem a ideia de parceria, a qual não necessita de um grupo envolvido para execução da mesma. A interdisciplinaridade não é pensada e nem existiria sem a base que a possibilita: as disciplinas. 
Atualmente, existe uma vasta produção científica que possui alguma conceituação sobre interdisciplinaridade, estando nas experiências e vivências de cada sujeito a sua percepção "de quê e de como" praticar interdisciplinaridade em sala de aula, em projetos ou, até mesmo, em seu cotidiano.

Se a interdisciplinaridade é somente algo a ser desenvolvido por pessoas ou uma atitude que está imbricada nas ações, são questões que já foram pensadas na história da educação e que, atual situação, serão ainda (re) pensadas, pois está implícito no modo de agir da sociedade e dos cidadãos, sejam eles alunos ou professores. Nesse sentido, o que resta é continuar na busca da interdisciplinaridade, através de inovações em projetos e dentro da sala de aula, desafiando os limites e pesquisando essas ações da educação.

\subsection{Curso de Licenciatura em Ciências da Na- tureza: Principais Características}

O Curso de Licenciatura em Ciências da Natureza da Universidade Federal do Pampa, do Campus Dom Pedrito, começou suas atividades no início do ano de 2012, com uma turma de 50 alunos. Por ser novo, o curso iniciou apenas com alguns profissionais da área da Educação, posteriormente, com o primeiro semestre em andamento, é que docentes da área das Ciências da Natureza começaram a integrar o corpo docente do curso.

Este curso tem como principal objetivo a formação de professores na área de Ciências da Natureza, ou seja, que tenham entendimento das áreas de Biologia, Física e Química, e, dessa forma, possa possibilitar seus egressos atuarem no Ensino Fundamental e Médio. O curso visa promover o desenvolvimento e a qualidade da educação na região e no munícipio, devido a ser o primeiro curso de formação de professores no Campus Dom Pedrito, por meio da formação de educadores capazes de atuar de maneira interdisciplinar no Ensino de Biologia, Física e Química.

De acordo com Projeto Pedagógico do Curso (PPC, 2012), a missão do curso é de:

[...] formar profissionais preparados para compreender a realidade social, na qual se insere a escola em que atua, e que seja dinâmico em atuar diante das rápidas transformações da sociedade. Além disso, a interdisciplinaridade proposta no curso de Licenciatura em Ciências da Natureza deverá estimular os alunos em sua curiosidade científica, incentivando-os à pesquisa e a reflexão ética perante a sociedade e a natureza, diante da perspectiva de aproveitamento das potencialidades locais para o desenvolvimento sustentável. (p. 18)

Devido a ser um curso noturno e apresentar a complexidade das três áreas - Biologia, Física e Química -, uma das características que deve ser ressaltada é o tempo de integralização, apresentando um total de 9 (nove) semestres. Possui uma carga horária total de 3230 horas, desenvolvida de segunda a sexta à noite e aos sábados pela manhã. Essas características do curso vão de encontro às necessidades de boa parte dos alunos ingressantes, já que muitos trabalham, ocasionando, desse modo, problemas como infrequência nos componentes curriculares do sábado, aumentando o índice de reprovação e evasão do curso.

Com recém duas turmas em andamento, o curso passa por constantes discussões e estudos pelo Núcleo Docente Estruturante (NDE), a fim de apresentar melhorias e flexibilidade nos componentes curriculares, assim como na sua estrutura, haja vista uma série de especificidades, como é o caso dos alunos que trabalham.

O NDE é composto por docentes das áreas de Biologia, Física e Química que se reúnem periodicamente com o intuito de problematizar e resolver questões referentes ao curso, como, por exemplo, modificações e alterações em componentes curriculares e no Projeto Pedagógico do Curso. Este grupo intensificou suas ações, visto o processo de reconhecimento pelo Ministério de Educação (MEC), que está em fase inicial; e manifestações feitas pelas turmas sobre os problemas existentes no curso.

Muitos são os desafios quando se pensa em curso de formação de professores interdisciplinares, pois há certa complexidade no processo de ensino-aprendizagem desse curso. Como exposto, cursos com uma característica interdisciplinar ainda não apresentam diretrizes curriculares, tornando o trabalho do grupo envolvido mais difícil, pois o embasamento utilizado consiste apenas de documentos que discutem a formação de professores da Educação Básica, sem abordar especificidades. No mês de maio do ano de 2013, a Secretaria da Educação Superior - SESu, através da Portaria 19, de 02 de maio de 2013, publicada no DOU de 06/05/2013 - Seção II - p. 23, constituiu um Grupo de Trabalho das Licenciaturas Interdisciplinares e Similares, para que, no prazo de 180 (cento e oitenta) dias, propusesse subsídios para o ordenamento dos referidos cursos. Até o momento nenhum documento foi divulgado por esse grupo de trabalho, porém espera-se que, em breve, legislações e normativas sejam constituídas para que sirvam de base para as licenciaturas interdisciplinares. Caso não haja certa rapidez de divulgação, inúmeras dúvidas e questionamentos continuarão permeando as escritas de projetos de curso de formação de professores interdisciplinares.

\section{Procedimentos Metodológicos: Analisan- do a Interdisciplinaridade em um curso de Licenciatura em Ciências da Natureza}

A abordagem metodológica utilizada nesse trabalho caracteriza-se por uma pesquisa de cunho qualitativo, envolvendo a fala dos sujeitos analisados. Para isso utilizou-se a Análise Textual Discursiva (ATD) de Moraes \& Galiazzi (2007) como método da análise dos dados, por 
perpassar pela análise textual e pela análise do discurso.

Este tipo de metodologia de análise inicia pela unitarização, ou seja, o corpus da pesquisa (materiais coletados para análise) é separado em unidades de sentido. Nesse momento, o pesquisador deve pensar nas partes constituintes do todo. As unidades de sentido ou de significado são quando o texto é transformado em unidades elementares, as quais correspondem a elementos discriminantes de sentidos e significados imprescindíveis para a finalidade da pesquisa (MORAES \& GALIAZZI, 2007).

Após o processo de unitarização, tem-se a categorização das unidades de sentido, a qual o pesquisador precisa perceber a articulação entre essas unidades e reunir as que possuem significados semelhantes. $\mathrm{O}$ processo de categorização se caracteriza por ser um período de reconstrução do desconstruído, implicando na construção gradativa do objeto de pesquisa, através da análise e interpretação das informações do conjunto das unidades. A categorização se diferencia por ser um momento de síntese, a qual necessita, de acordo com Moraes \& Galiazzi (2007, p. 74), de "uma organização, um ordenamento e um agrupamento, sempre buscando expressar novas compreensões dos fenômenos investigados".

Como último ato da análise, o pesquisador transforma essas categorias em textos, de forma a abarcar várias reconstruções, tornando as categorias em metatextos. Moraes \& Galiazzi (2007) apresentam essa ação de escrever como a união de pesquisador e sujeitos de pesquisa.

Essa produção escrita, concretizada a partir das análises e interpretações de uma investigação, não constitui expressão objetiva dos conteúdos de um "corpus" de análise, mas representa construções e interpretações pessoais do pesquisador, tendo sempre como referência fidelidade e respeito às informações obtidas com os sujeitos de pesquisa. (p. 94)

A utilização dessa análise trata de uma ferramenta aberta, que exige dos usuários aprender a conviver com uma abordagem que demanda constantemente a (re) construção de caminhos (MORAES \& GALIAZZI, 2006).

Nesse sentido, a ATD foi utilizada como forma de (re) construção das percepções sobre interdisciplinaridade, a partir das concepções de professores e acadêmicos envolvidos no curso de Licenciatura em Ciências da Natureza.

\section{Resultados e Discussões: Concepções dos Docentes e Discentes}

A pesquisa foi realizada para investigar como docentes e licenciandos de um curso interdisciplinar de Ciências da Natureza percebem a interdisciplinaridade dentro do curso, isto é, como está sendo trabalhada dentro da sala de aula e o que a interdisciplinaridade está acrescentando na formação dos acadêmicos. Para obter esses dados, realizou-se a aplicação de um questionário com 30 (trinta) licenciandos que estavam no $1^{\underline{0}}$ e $3^{\circ}$ semestre do curso e 6 (seis) professores que ministram aulas no curso.

Baseado nos documentos oficiais e a partir da fala dos docentes e discentes, percebe-se que as mudanças tornam-se significativas para a formação dos licenciandos, pois estes terão que, a partir da sua formação no curso de graduação, obter uma visão mais ampla e diversificada nas áreas do conhecimento.

O processo de análise iniciou-se com a unitarização, em que o pesquisador examinou os questionários aplicados para professores e alunos, a fim de atingir as unidades de sentido, como mostra a Figura 1. Podemos observar que já nessa fase da ATD aparecem os indicadores que possibilitaram perceber a relação entre as unidades e, assim, formar as categorias com os textos dos quais se originam (MORAES \& GALLIAZZI, 2007).

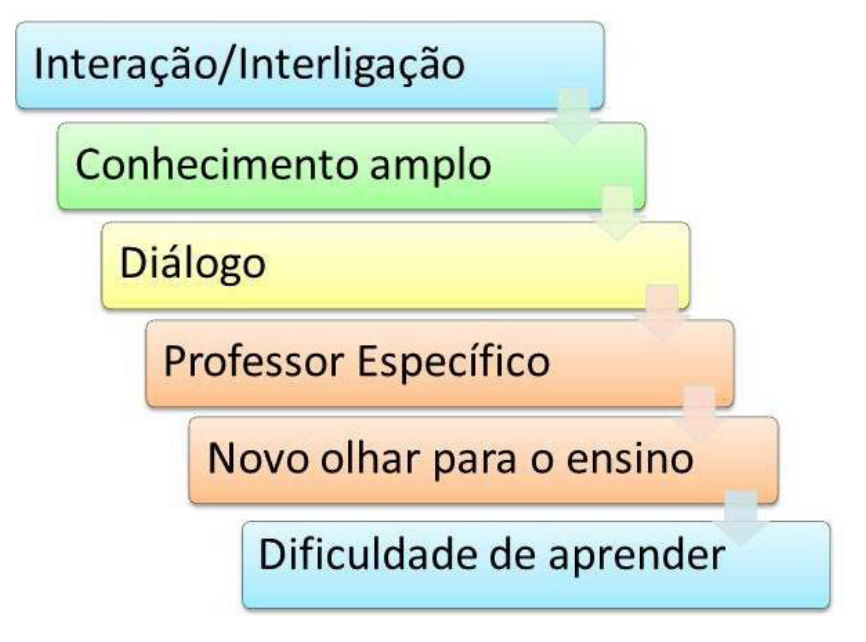

Figura 1: Unidades de Sentido

As unidades de sentido que emergiram no momento da unitarização mostram que os conceitos envolvidos, quando se trata do assunto interdisciplinaridade, carecem de interação e diálogo entre as disciplinas, gerando um conhecimento amplo, em que para muitos se torna uma nova forma de compreender e fazer o ensino e aprendizagem.

Após o procedimento de unitarização, pode-se iniciar o processo de categorização. Essa fase da ATD é como um "quebra-cabeça", as peças são organizadas e colocadas de acordo com a pesquisa realizada e o olhar do pesquisador. Sendo assim, cada pesquisa encontrará um significado para a análise. As Figuras 2 e 3 mostram o processo de categorização, desde as categorias iniciais até as finais.

Deste modo, ao alcançar-se as unidades de sentido e organizar os pontos em comum em três categorias, monta-se o "quebra-cabeça", emergindo a categoria final, que apresenta relação com o eixo central aplicado nas novas Licenciaturas, baseadas em um ensino inter- 


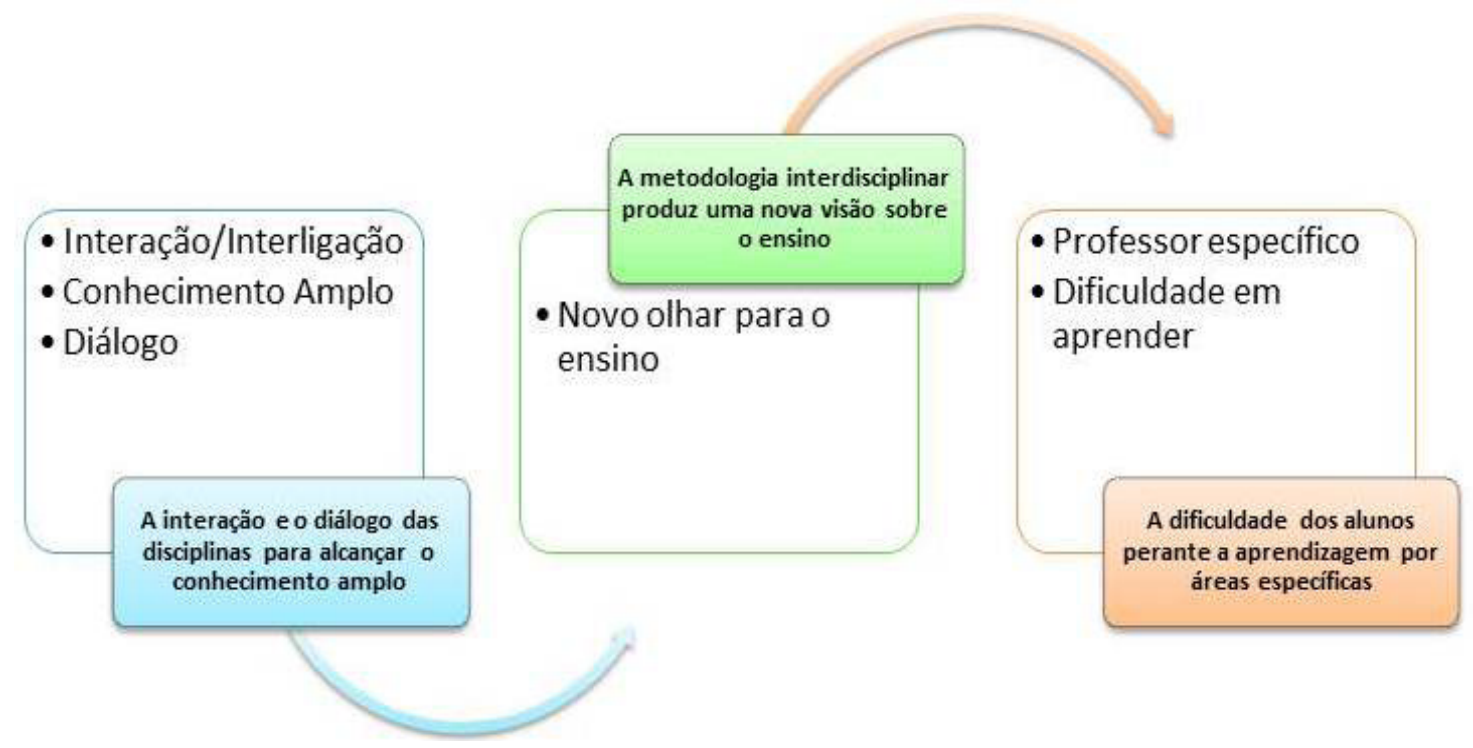

Figura 2: Categorias Iniciais

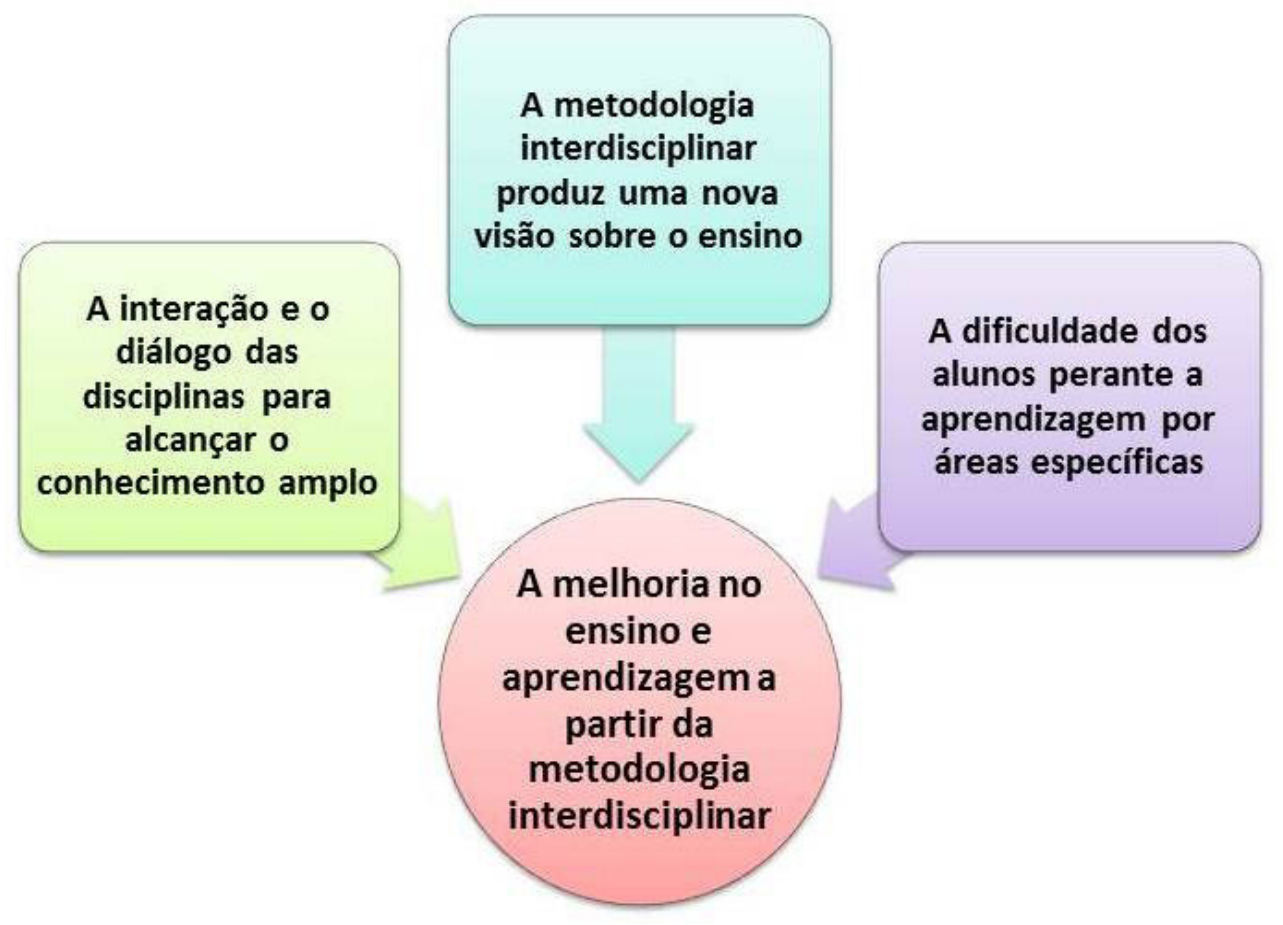

Figura 3: Categoria Final 
disciplinar. Nesse sentido, o produto final da ATD se comporta como um metatexto, onde neste a análise tem a forma de um texto composto de respostas e discussões sobre a categoria final emergente, em diálogo com os sujeitos de pesquisa e os teóricos, que já problematizam algumas dessas questões.

$\mathrm{O}$ resultado da pesquisa mostra que a maioria dos discentes e docentes tem por entendimento a interdisciplinaridade como disciplinas interligadas que desenvolvem um conhecimento amplo e que necessitam de um diálogo entre elas. Apenas alguns demonstraram dificuldade em compreender a visão interdisciplinar do curso. Além disso, a partir da última categoria, conclui-se que o ensino por áreas específicas ou através de disciplinas (Biologia, Física e Química), separadamente, gera um grau maior de complexidade, para a aprendizagem dos acadêmicos, e, para os docentes, gera insegurança, pois eles expõem que se torna mais complicado de ensinar, devido a suas formações específicas.

Os docentes ententem interdisciplinaridade como uma articulação/integração entre as áreas do conhecimento, como explana o professor B: "a interdisciplinaridade propõe-se a discutir e superar a estagnação e fragmentação da disciplinaridade através da cooperação das diferentes áreas de conhecimento." Porém, ao questionados sobre o "ser interdisciplinar na prática", a maioria dos professores entende por prática interdisciplinar aquela que acontece quando o docente perpassa várias áreas do conhecimento, mesmo que solitário.

A contrariedade e o reflexo da insegurança da interdisciplinaridade se mostram transparentes nas falas, pois os docentes acreditam que por ser um curso intitulado interdisciplinar que irá formar professores em uma área do conhecimento, somente este fato já basta. Além da insegurança, os professores se sentem desconfortáveis quando ultrapassam os limites estritos da área disciplinar na qual aprenderam a se deslocar em consequência de sua formação tradicional. Muitas vezes, existe consciência de que a abordagem interdisciplinar oferece ganho significativo para os alunos, porém a barreira que se faz presente torna-se ampla, gerando certa resistência pela busca da interdisciplinaridade (PIETROCOLA et al., 2003).

O professor D expõe que a interdisciplinaridade pode ocorrer quando são dados exemplos em sala de aula que escapa da sua disciplina: "relaciono as disciplinas e também os conteúdos, torno o conteúdo contextualizado, ou seja, procuro mostrar as relações sociais, políticas, culturais, econômicas, o que vai além de uma única área". Porém, o professor A não percebe, ainda, a formação dos acadêmicos interdisciplinares da forma com que o curso e as componentes curriculares estão dispostas:

(...) a formação de um acadêmico em Ciências da Natureza será interdisciplinar somente se tivermos docentes interdisciplinares, pois da forma como se encontra, cada professor trabalhando separadamente na sua disciplina, não percebo a interdisciplinaridade ocorrendo no curso". (Professor A)

Os discentes percebem que não ocorre a conversa entre as componentes curriculares: “[...] o curso ainda está no método de matérias compartimentadas, ou seja, Química, Física e Biologia" (Licenciando 20).

O licenciando 2 expõe, de forma clara, a preocupação da formação dos mesmos não se caracterizar interdisciplinar, devido aos professores formadores não conseguirem atuar interdisciplinarmente.

Na formação da nossa turma, até o momento não está acrescentando em nada, pois as disciplinas teriam que trabalhar juntas, e, isso não acontece, até então o curso está sendo disciplinar, então também acho que não seremos ou não saberemos ser professores interdisciplinares. (Licenciando 2)

[...] ensinam, mas não fazem, só funciona na teoria. Acho que nossos professores não sabem ainda como funciona, mas vão cobrar do nosso curso. (Licenciando 7)

Pode-se perceber na fala dos alunos a indignação em relação à interdisciplinaridade não ser exercida dentro do curso, pois, como muitos explicitam, essa faz parte do curso, seja no PPC ou na teoria colocada pelos docentes, todavia, não é executada.

Ressalta-se, como explicita Fazenda (2003, p. 50), que "hoje, mais do que nunca, reafirmamos a importância do diálogo, única condição possível de eliminação das barreiras entre as disciplinas". A partir disso, emergem várias questões: Como formar licenciados em um curso interdisciplinar, sendo que o corpo docente parte de uma formação disciplinar/específica? Partindo do pressuposto que, para ser interdisciplinar, deve haver um diálogo entre as áreas do conhecimento, como incentivar e propiciar essa conversa em um corpo docente que percebe a interdisciplinaridade como momento solitário?

De acordo com Fazenda (2003, p. 51), "a rigidez dos educadores, enquadrados em rígidas formas, é talvez o obstáculo mais difícil". Entretanto, outros autores já trazem a visão da interdisciplinaridade ocorrendo através de um único sujeito e pela fragmentação, criticando o modelo que se imagina de interdisciplinaridade, ou seja, parceria e diálogo entre várias disciplinas, como expõem Jantsch \& Bianchetti (2011):

[...] a obtusidade desta visão se revela ainda quando não se percebe que o apelo ao trabalho de cooperação (chamado de parceria) traz também a subjacente a "nova" face e fase do capital, em sua sempre renovada tentativa de perenizar-se. [...] a "nova" proposta de trabalho em parceria tende a se revelar como um "novo" enjaulamento, um autoenredamento em claro destino auto fágico. (p. 27)

No entanto, para os estudantes, o ensino dialogado entre as componentes curriculares proporciona um 
entendimento melhor e a percepção do todo, e não somente das partes. Observam-se alguns trechos da fala dos acadêmicos sobre interdisciplinaridade:

“É aquilo que faz a ligação entre as disciplinas, realizando integração, complemento e abrangendo o conhecimento e o tornando mais amplo. Onde o foco é instigar o aluno, buscando cada vez mais o seu interesse." (Licenciando 5)

“Interação de várias disciplinas, diferentes percepções, ou seja, a ligação de várias matérias, trabalhadas em um único conteúdo." (Licenciando 12)

Percebe-se que a interdisciplinaridade ainda é algo que se encontra distante dos professores, seja na Educação Básica, seja no Ensino Superior. Os docentes e discentes sabem na teoria o que pode se tornar interdisciplinar no ensino dos conteúdos em sala de aula, porém na prática compreendemos que as aulas ainda estão longe de se tornarem interdisciplinares.

Essa temática transcende muito mais do que um simples conhecimento, para isso o estudo deve ser constante, sendo que a interdisciplinaridade só será alcançada com dedicação mútua de pesquisar, estudar e dialogar com as áreas do conhecimento. A interdisciplinaridade não visa à eliminação das disciplinas, mas, sim, a interligação, pois a mesma depende delas, auxiliando na formação de sujeitos de visão crítica e diferenciada, que consigam expor suas opiniões e, com isso, criar seus próprios conceitos.

Vários são os desafios que desabrocham quando se fala de uma temática que proporciona muitas discussões há muito tempo. Contudo, a partir do desafiar e dialogar é que haverá uma reflexão maior dos docentes sobre sua prática dentro de um curso de formação de professores interdisciplinares, mesmo que sua base tenha partido de uma formação específica e linear.

\section{Conclusões}

Com a discussão e investigação sobre como professores e futuros licenciandos constituem a conceituação e a prática da interdisciplinaridade, nota-se que este tema ainda é inovador para muitos, pois exige dos sujeitos entendimento e conhecimento maior sobre cada área estudada. No entanto, percebe-se que, para a interdisciplinaridade ser alcançada, é necessário ter um olhar amplo, visando sempre à busca do ensino contextualizado e instigador.

De acordo com Favarão \& Araújo (2004, p. 109): “a necessidade da interdisciplinaridade impõe-se não só como forma de compreender e modificar o mundo, mas como uma exigência interna das ciências que buscam o restabelecimento da unidade perdida do saber".

É importante levar em consideração que esse tipo de ensino vem sendo implantado aos poucos nas univer- sidades e, há algum tempo, foram realizadas algumas tentativas de inserção de práticas interdisciplinares na Educação Básica, mas, como o estudo e a aplicação é recente nos cursos de licenciaturas interdisciplinares, os docentes envolvidos nesses cursos ainda não possuem uma formação específica, dificultando a execução das propostas.

Após uma reflexão sobre como a interdisciplinaridade já está sendo pensada e discutida, de formas variadas, percebe-se isso como um primeiro passo a ser dado dentro das instituições. Em alguns momentos nota-se ainda que a interdisciplinaridade faz parte somente do discurso teórico dos sujeitos envolvidos, mas a atitude de instigá-los em um processo reflexivo e desafiador pode ser uma das maneiras de fazer com que a teoria se transforme na prática.

Os estudantes formados, neste momento, dependerão de professores que buscam entender, interagir com seus pares, dialogar e perceber a necessidade de se envolver e fazer da sala de aula uma prática interdisciplinar, visto a concepção dos cursos de formação de professores interdisciplinares. Porém, compreende-se que há um último ponto emergente, a formação de docentes interdisciplinares, a qual poderá se tornar a forma final de introdução das práticas interdisciplinares na Educação. Esse ponto vem ao encontro das Licenciaturas Interdisciplinares, ou seja, na formação desses licenciandos é que existirá o momento de inserção da interdisciplinaridade no mercado de trabalho não somente na teoria, mas na prática também. Dessa forma, possivelmente, haverá professores com uma formação ampla e que, provavelmente, terão outra visão de ensino e de mundo. Todavia, não se pode afirmar, ainda, que estes acadêmicos se constituirão interdisciplinares e que suas práticas docentes assim serão, sendo isso o caminho para futuras pesquisas na temática da interdisciplinaridade.

\section{Agradecimentos}

Aos sujeitos de pesquisa, ou seja, docentes e discentes envolvidos no curso de Ciências da Natureza do Campus Dom Pedrito da UNIPAMPA. E a UNIPAMPA pela bolsa PBDA 2013, concedida no Projeto de Pesquisa Ensino de Ciências da Natureza: Diálogos interdisciplinares em rodas de formação.

\section{Referências}

BRASIL. Secretaria de Educação Média e Tecnológica: Parâmetros Curriculares Nacionais para o Ensino Médio. Ciências da Natureza, Matemática e suas Tecnologias. Brasília: MEC, SEMTEC, 2000.

BRASIL. Secretaria de Educação Média e Tecnológica: Orientações Educacionais Complementares aos 
Parâmetros Curriculares Nacionais. Física. Brasília: Ministério da Educação/Secretaria de Educação Média e Tecnológica, 2002.

BRASIL. RESOLUÇÃO CNE/CEB № 2, DE 30 DE JANEIRO 2012. Define Diretrizes Curriculares Nacionais para o Ensino Médio. Disponível em < http://portal.mec.gov.br/index.php?option=com_ content\&view=article\&id=17417\&Itemid=866>. Acesso em: 20 Abr. 2013.

\section{BRASIL. CONSTITUIÇÃO DE GRUPO DE} TRABALHO DAS LICENCIATURAS INTERDISCIPLINARES E SIMILARES. Secretaria da Educação Superior - SESU, através da Portaria 19, de 02 de maio de 2013, publicada no DOU de 06/05/2013 - Seção II - p. 23. Disponível em: < http://pesquisa.in.gov.br/imprensa/jsp/visualiza/ index.jsp? jornal $=2 \&$ pagina $=23 \&$ data $=06 / 05 / 2013>$. Acesso em: 30 Out. 2013.

FAVARÃO, N. R. L.; ARAÚJO, C. S. A. Importância da Interdisciplinaridade no Ensino Superior. EDUCERE - Revista da Educação, vol. 4, n.2, p. 103115, 2004.

FAZENDA, I. C. A. Interdisciplinaridade: Qual é seu sentido? São Paulo: Paulusm 2003.

FERREIRA, M. E. M. P. Ciência e Interdisciplinaridade. In: FAZENDA, I. Práticas Interdisciplinares na escola. São Paulo: Cortez, 1999.

LUCK, H. Pedagogia interdisciplinar: fundamentos teórico-metodológicos. 9 ed. Petrópolis: Vozes, 2001.

JANTSCH, A.P.; BIANCHETTI, L. (orgs.). Interdisciplinaridade: além da filosofia do sujeito. Petrópolis: Vozes, 2011.

JAPIASSÚ, H. Interdisciplinaridade e Patologia do Saber. Rio de Janeiro: Editora Imago, 1976.

MIRANDA, E. M.; ALVES, A. R.; MENTEN, M. L. M.; FREITAS, D.; ZUIN, V. G.; PIERSON, A. H. C. ENEM 2009: articulações entre CTS, interdisciplinaridade e contextualização evidenciadas nas questões das Ciências da Natureza. In: II Seminário Ibero-Americano Ciência-Tecnologia-Sociedade no Ensino das Ciências. Distrito Federal: Universidade de Brasília, 2010.

MORAES, R.; GALIAZZI, M. C. Análise Textual Discursiva: processo reconstrutivo de múltiplas faces. Ciência \& Educação, v. 12, n. 1, p. 117-128, 2006.

MORAES, R.; GALIAZZI, M. C. Análise Textual Discursiva. Ijuí: Editora UNIJUÍ, 2007.

PIETROCOLA, M; ALVES FILHO, J. P.; PINHEIRO, T. F. Prática Interdisciplinar na formação disciplinar de professores de Ciências. Investigações em Ensino de Ciências, v.8, p. 131-152, 2003.

Universidade Federal do Pampa - Campus Dom Pedrito. Projeto Pedagógico do Curso de Ciências da Natureza. 2012.

YARED, Ivone. O que é Interdisciplinaridade? In: FAZENDA, Ivani (org). O que é Interdisciplinaridade? São Paulo: Cortez, 2008. 